Vol. 5, No. 1, 2019

\author{
Yuriy Molkov ${ }^{1}$, Yaroslav Ivanyts'kyi ${ }^{2}$, Taras Lenkovs'kyi ${ }^{3}$, \\ Andriy Trostianchyn ${ }^{4}$, Volodymyr Kulyk ${ }^{5}$, Roman Shyshkovskyy ${ }^{6}$
}

1. Department of Strength and Durability of Structures under Complex Loading, Karpenko Physico-mechanical Institute of the NAS of Ukraine, Ukraine, Lviv, Naukova street 5, E-mail: molkov@ipm.lviv.ua

2. Department of Strength and Durability of Structures under Complex Loading, Karpenko Physico-mechanical

Institute of the NAS of Ukraine, Ukraine, Lviv, Naukova street 5, E-mail: dep-12@ipm.lviv.ua

3. Department of Strength and Durability of Structures under Complex Loading, Karpenko Physico-mechanical

Institute of the NAS of Ukraine, Ukraine, Lviv, Naukova street 5, E-mail: lenkovskiy@ipm.lviv.ua

4. Department of Applied Materials Science and Materials Engineering, Lviv Polytechnic National University,

Ukraine, Lviv, S. Bandery street 12, E-mail: andrii.m.trostianchyn@lpnu.ua

5. Department of Applied Materials Science and Materials Engineering, Lviv Polytechnic National University,

Ukraine, Lviv, S. Bandery street 12, E-mail: volodymyr.v.kulyk@1pnu.ua

6. Department of Bridges and Structural Mechanics, Lviv Polytechnic National University, Ukraine, Lviv, S. Bandery street 12, E-mail: ombm.dept@1pnu.ua

\title{
EXPERIMENTAL DETERMINATION OF CRITICAL STRAIN ENERGY DENSITY OF DUCTILE MATERIALS
}

Received: May 15, 2019 / Revised: June 20, 2019 / Accepted: June 26, 2019

(C) Molkov Yu., Ivanyts'kyi Ya., Lenkovs'kyi T., Trostianchyn A., Kulyk V., Shyshkovskyy R., 2019

\begin{abstract}
The method of experimental determination of strain energy density of plastic materials is developed. The technique for complete true stress-strain curves plotting is formulated. The standard hydraulic testing machine is equipped with specially designed experimental setup for Bridgman specimens testing at strain controlled tension loading with digital camera and light source for using digital image correlation method - a non-contact technique for strain and displacement measurement. The digital image correlation method was used to determine the local strain at the onset of fracture in the neck of Bridgman specimen. The technique takes into account the change of cross-section area in the neck of specimen due to internal crack propagation when calculating the true stresses. The complete true stress stress-curve of $40 \mathrm{Kh}$ alloyed steel is plotted end critical strain energy density of steel is determined from it. It is shown that the critical strain energy density of material, determined from the curve obtained by developed technique is 1.8 times higher than determined from the classical true stress-strain curve and is close to the value of the specific heat of fusion of steel. The curves built using the proposed technique can be used for setting material properties in stress-strain state calculations by finite element method at large scale yielding conditions, for instance at pressure vessels critical pressure calculation. The critical strain energy density value can be considered as a material property at fatigue life-time calculation using energy approach.
\end{abstract}

Keywords: strain energy density, stress-strain curve, true stress, true strain, Bridgman specimen, digital image correlation, strain-controlled loading, alloyed steel.

\section{Introduction and problem statement}

For the correct calculation of the stress-strain state by the finite element method at large scale yielding conditions [1], as well as the calculation of the strength and service life of structural elements by energy approach [2-4], it is necessary to have a stress-strain curve in terms of true stresses and strains, as well as the value of strain energy density of material. At tension of a standard dog-bone specimen, a central crack is formed in the neck of the specimen after reaching the ultimate stress, which at further loading propagates from the centre of the specimen to the outer surface. Due to the crack propagation the residual 


\section{Yuriy Molkov, Yaroslav Ivanyts 'kyi, Taras Lenkovs 'kyi, Andriy Trostianchyn, et al.}

cross-section area in the neck of the specimen sharply decreases, while the stress in this ring-shaped crosssection continue to increase. When constructing stress-strain curves, both engineering and true, this effect is usually neglected, leading to significant error in determination of critical stresses and strains of materials which are determined by the end point of the curve. Therefore, the aim of this work is to develop a technique for complete true stress-strain curves plotting and strain energy density of plastic materials determination.

\section{Specimens, technique and equipment}

The appropriate technical means and technique for tensile testing of Bridgman specimen under strain-controlled loading conditions was developed.

Bridgman specimens [5] was slightly modified in order to ensure their easy mounting into loading setup and rigid fixation (Fig. 1). For this purpose, the specimens have asymmetrical full-threaded gripping parts. The specimens were made of $40 \mathrm{Kh}$ steel (analogues $5135,37 \mathrm{Cr} 4$ ) in the delivery state, the standard mechanical properties of which are as follows: yield stress $\sigma_{0,2}=450 \mathrm{MPa}$, ultimate stress $\sigma_{U}=860 \mathrm{MPa}$, relative elongation $\delta_{5}=16 \%$, relative stiffness $\psi=50 \%$. The gage area of the specimen was polished and the stochastic speckle pattern was applied on it using special elastic paint. This is necessary in order to use non-contact digital image correlation (DIC) technique [6-8] for strain measurement.

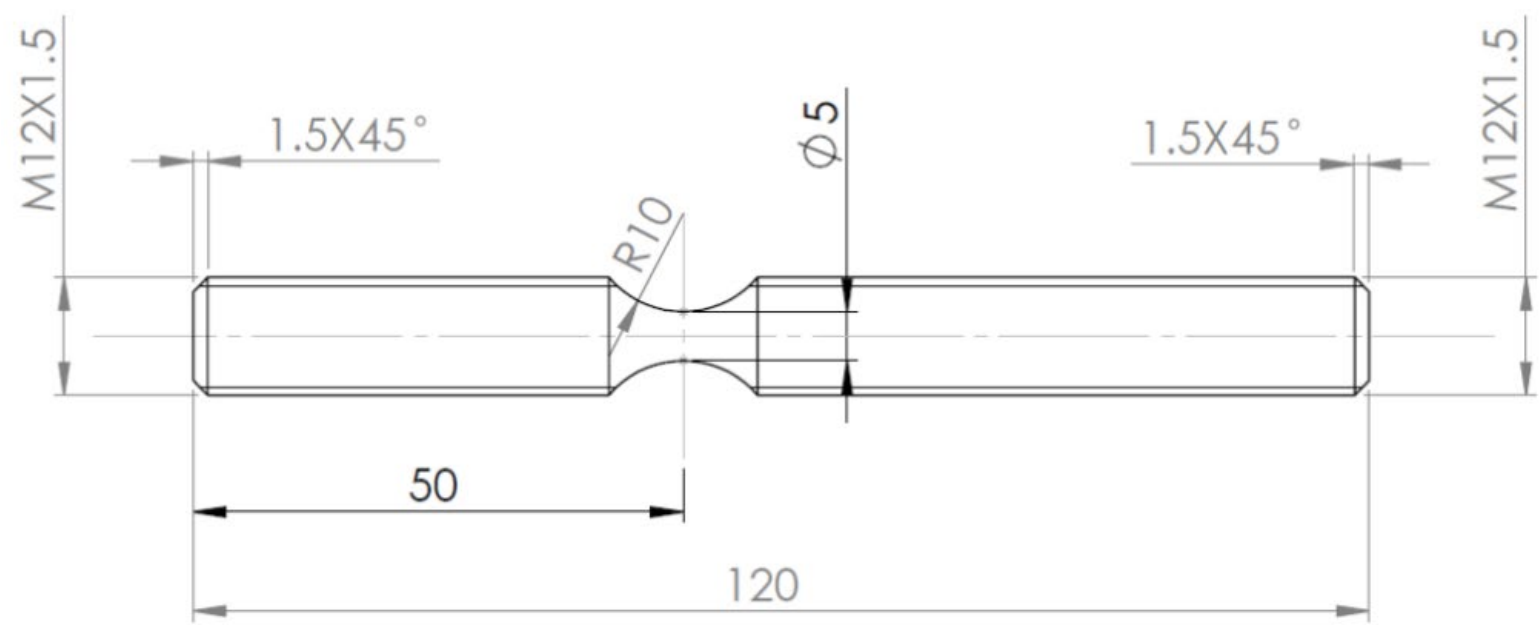

Fig. 1. Modified Bridgman specimen for complete true stress-strain curves plotting

The DIC technique was used for full-field analysis of strain and displacement distribution on the surface of gage area of the specimen. Since the initiation and propagation of crack during loading of the specimen beyond the ultimate stress occurs spontaneously due to elastic deformation energy accumulated in the intermediate links of testing machine, which in standard machines are not rigid enough, a special loading setup was developed for tensile testing of the specimens (Fig. 2). The setup allows to achieve smooth thoroughly strain controlled loading of the specimen, which avoids rapid spontaneous fracture, and allows to capture the image of the specimen surface at a time as close as possible to the fracture.

The setup consists of an elastic steel ring and gripping cylinders, to which the force is transmitted through special forks from the standard hydraulic testing machine P-100. The upper gripping cylinder has a threaded hole for mounting the specimen, and the lower one has a hole with a step that serves as a rest for a nut screwed up on the opposite treaded end of the specimen. This mounting system makes possible to fasten the specimen after preloading the setup and compensating all gaps. An extensometer was used to measure the elastic deformation of the ring. The force on the specimen is the difference in readings of the machine's force meter and the force on the ring itself, which was measured by the extensometer calibrated in force units. The force on the sample $P_{\mathrm{S}}$ were calculated by formula:

$$
P_{\mathrm{S}}=P_{\mathrm{M}}-P_{\mathrm{R}},
$$

where $P_{\mathrm{M}}$ is the force of the machine, $P_{\mathrm{R}}$ is the resistance force of the elastic ring. 


\section{Experimental Determination of Critical Strain Energy Density of Ductile Materials}

Images for DIC processing were recorded using an optical system on the base of Toupcam UCMOS 10000KPA industrial digital camera and Xenoplan objective lens. Images were recorded at $0.5 \mathrm{fps}$ with resolution $3584 \times 2748$ pixels. After image processing using DIC software, local strain and displacement distributions in the gage area of the specimen at different loading stages were obtained (Fig. 3a) by analyzing which the maximal strain point was found. For this point the strain table data were extracted for further processing. The step of strain map calculation by DIC method, which corresponds to local strain measurement spacing, for steel $40 \mathrm{Kh}$ was taken equal to $50 \mu \mathrm{m}$ according to the criteria described in [9].

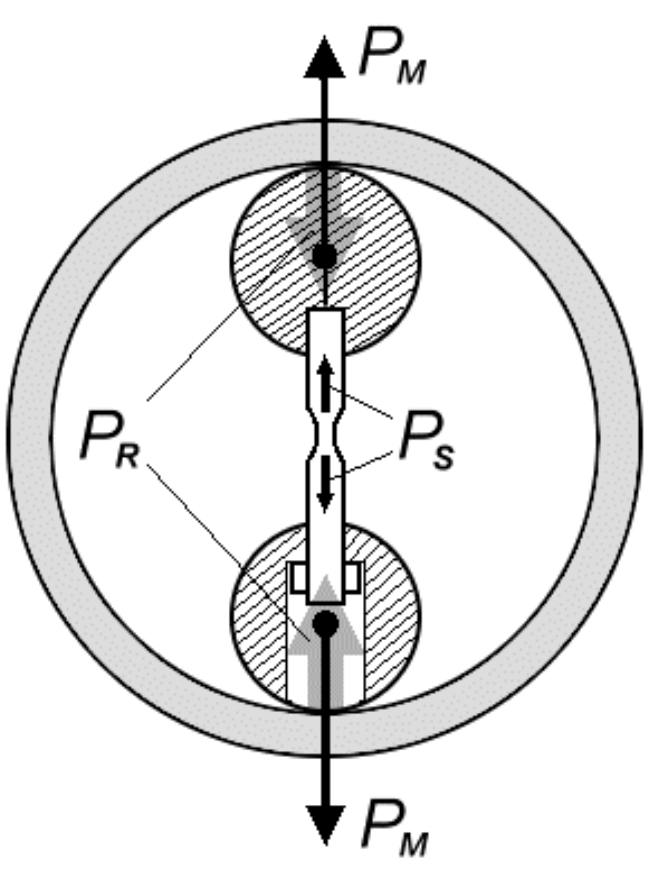

a

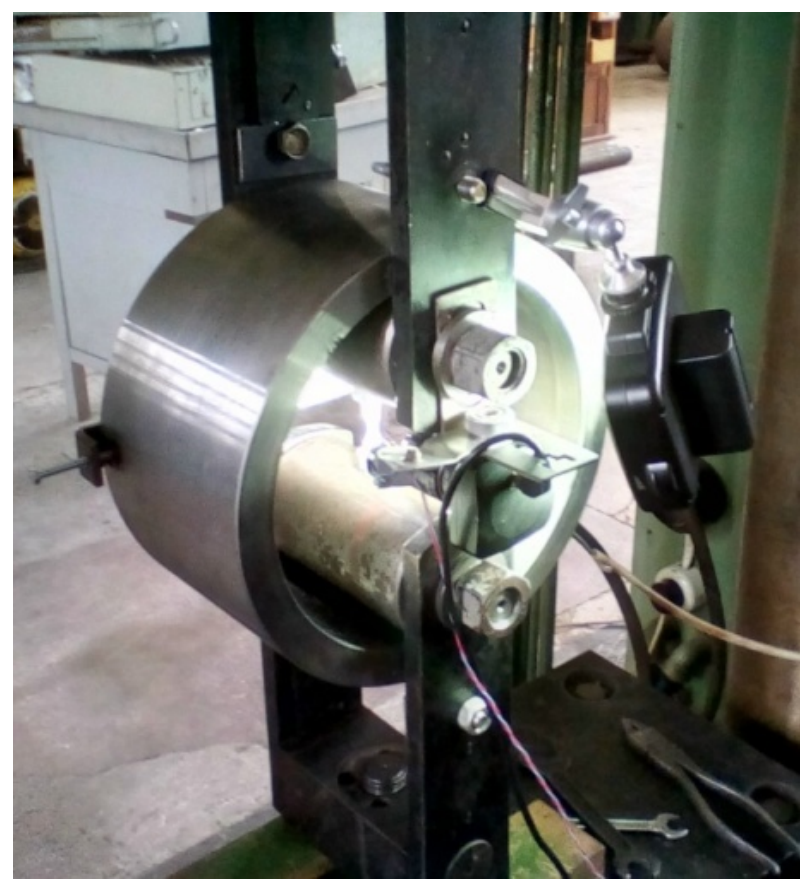

b

Fig. 2. Scheme (a) and general view (b) of the setup for strain-controlled loading installed on P-100 testing machine

To measure the size of the internal crack, several specimens were unloaded after achieving different levels of force beyond the force corresponding to engineering ultimate stress, then removed from the setup and grinded in the gage area to a depth of half diameter (Fig. 3b). Measurement of the crack front diameter was carried out with a microscope MIM-6.

The true stresses in the neck of the specimen were calculated as described in [10] before the crack appearance, and after its appearance by formula:

$$
S=\frac{P}{\frac{\pi}{4}\left(D_{n}^{2}-D_{c}^{2}\right)},
$$

where $P$ is the force applied to the specimen, $D_{n}$ is the diameter of the specimen in the neck, and $D_{c}$ is the diameter of the internal crack.

On the base of calculated true stresses and local strains measured by DIC method a complete true stress-strain curve of the material in the point of maximal strain was built. The critical strain energy density was determined as the area bounded by the curve and the strain axis. For this purpose, the experimentally obtained curvilinear section of the curve was approximated by a power function of the form:

$$
S(e)=A e^{B},
$$

where $A$ and $B$ are approximation coefficients.

Since in the neck of the specimen at tension the three-axis stress-strain state occurs, it was assumed that deformation of the elementary volume of material near the surface of the neck occurs in the directions of the three principal stresses. Then, to deform the material in each direction the certain part of energy will be spent. 
Yuriy Molkov, Yaroslav Ivanyts 'kyi, Taras Lenkovs 'kyi, Andriy Trostianchyn, et al.

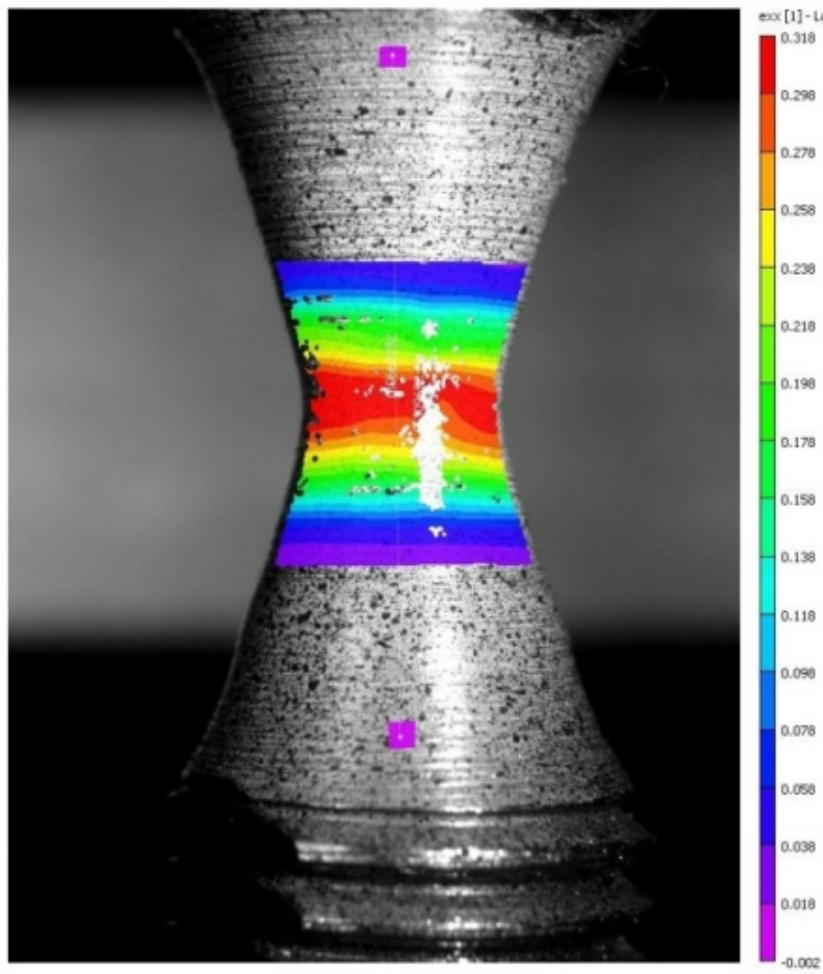

a

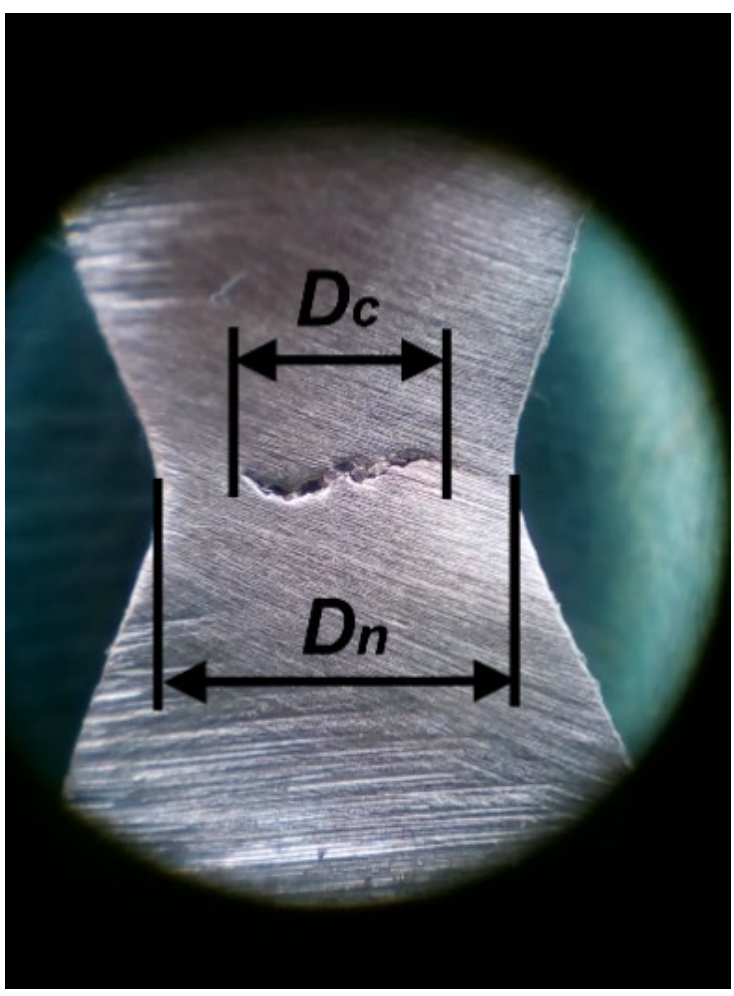

$\mathrm{b}$

Fig. 3. Strain distribution in the gage area of specimen obtained by DIC method (a) and internal crack size measurement (b)

Total strain energy density was therefore defined as the sum of the components of energy spent on deforming of an elementary volume of material in three principal directions and the fracture criteria was written as follows:

$$
W=W_{x}+W_{y}+W_{z}=W_{C},
$$

where $W_{\mathrm{C}}$ is critical strain energy density and the components of energy $W_{x}, W_{y}, W_{z}$ are defined as the area under the corresponding stress-strain curve by the formulae:

$$
\begin{aligned}
& W_{x}=\int_{0}^{\varepsilon_{x}} S_{x}\left(e_{x}, e_{y}, e_{z}\right) d e_{x}, \\
& W_{y}=\int_{0}^{\varepsilon_{y}} S_{y}\left(e_{x}, e_{y}, e_{z}\right) d e_{y}, \\
& W_{z}=\int_{0}^{\varepsilon_{z}} S_{z}\left(e_{x}, e_{y}, e_{z}\right) d e_{z},
\end{aligned}
$$

\section{Results and discussion}

As a result of the tests, the original curve "Force - Local strain" was obtained (Fig. 4a). On this curve point 1 corresponds to the moment of internal crack initiation, the section between points 1 and 2 corresponds to crack propagation from the centre of the specimen to the surface, and the sharply declining section after point 2 corresponds to spontaneous fracture of residual ring-shaped cross-section of the neck. After the true stress calculation, a complete true stress-strain curve of $40 \mathrm{Kh}$ steel was plotted on the base of the initial curve (Fig. 4b, curve 3).

As we can see, the critical values of stresses and strains on the obtained curve are higher than on classical true curve (Fig. 4b, curve 2), and much higher than the ultimate stress and elongation of $40 \mathrm{Kh}$ steel, determined from the engineering curve (Fig. 4b, curve 1).

The classical and complete true curves were approximated by the functions of Eq. (3) and the strain energy density of $40 \mathrm{Kh}$ steel according to Eq. (4) and (5) was calculated as the area bounded by the curve and the strain axis (Fig. 5, Table 1). 

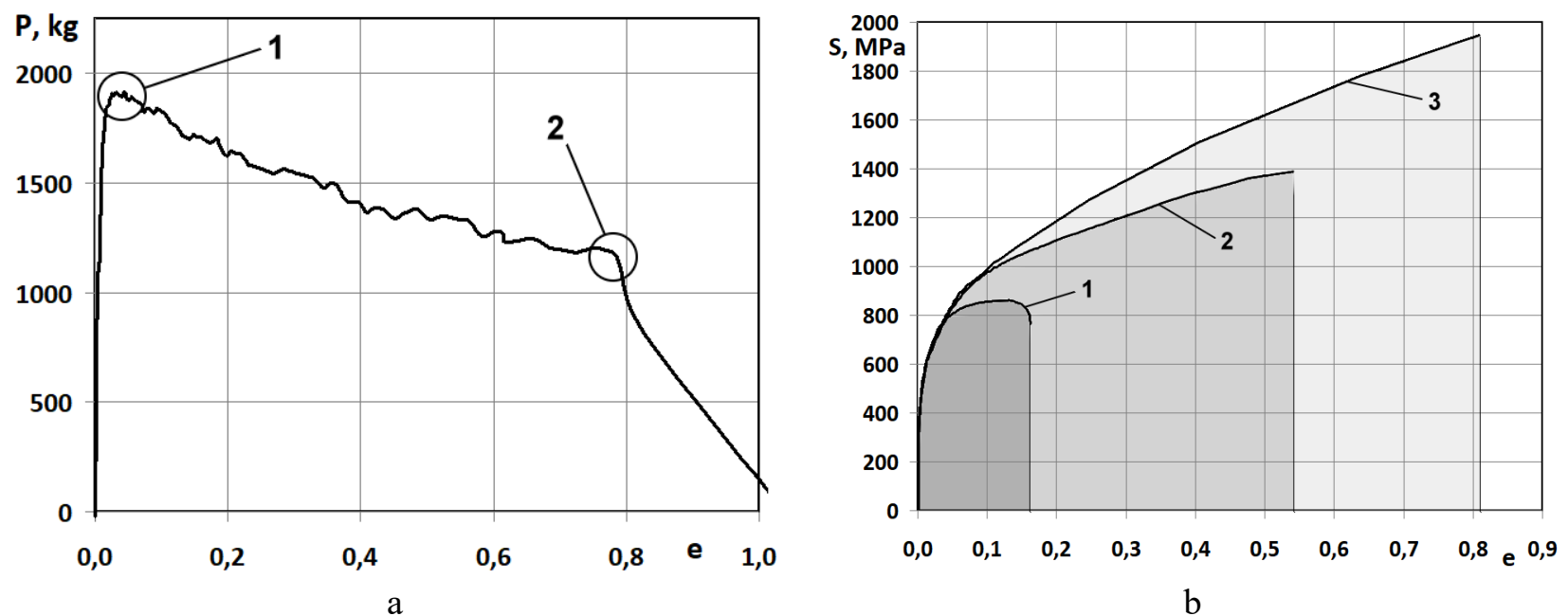

Fig. 4. Original curve "Force - Local strain" (a) and stress-strain curves of 40Kh steel (b): 1 - engineering curve, 2 classical true stress-strain curve, 3 - complete true stress-strain curve

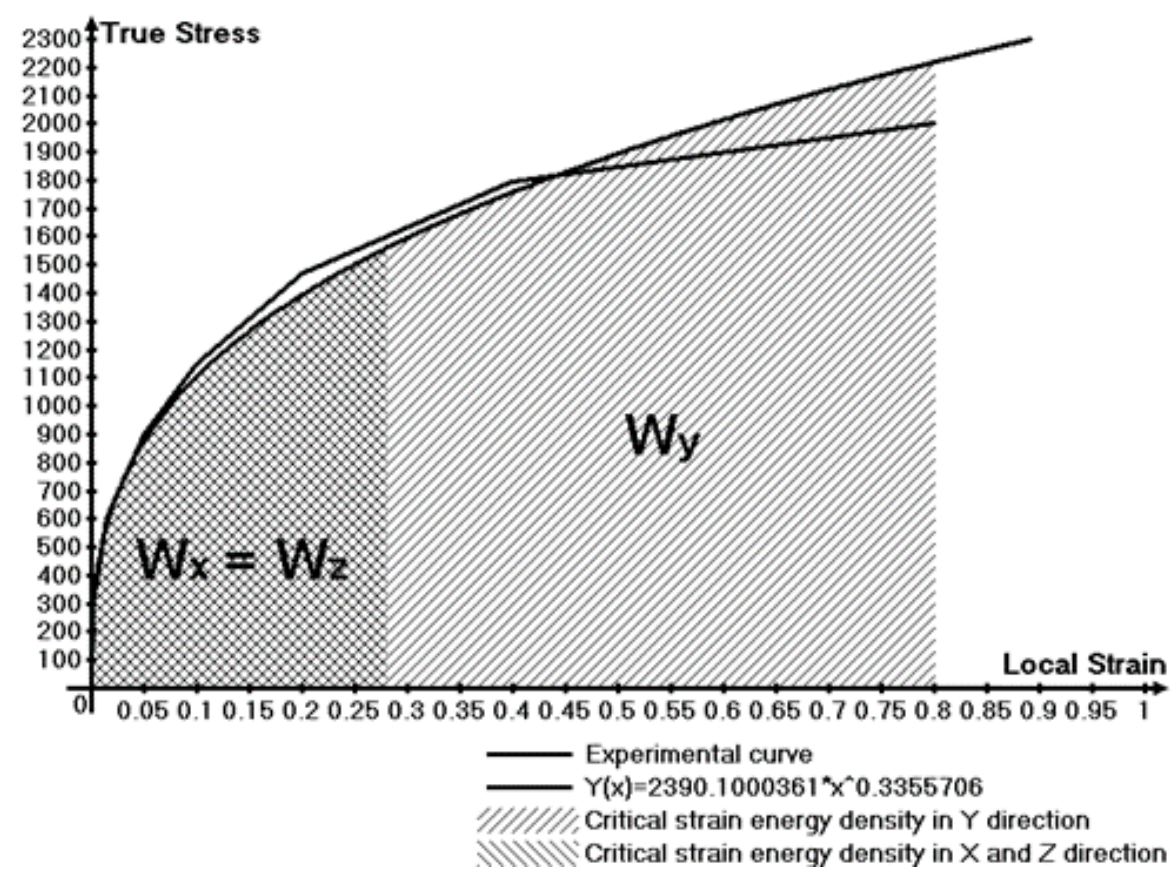

Fig. 5. Determination of strain energy density of $40 \mathrm{Kh}$ steel

Comparison of strain energy density values determined from the classical true and complete true curves shows that that the complete curve gives almost 1.8 times higher energy value. This value is close to the value of the specific heat of fusion (enthalpy) of 40Kh steel [11], expressed in energy density units $(\mathrm{MJ} / \mathrm{m} 3)$, which proves its correctness.

Table 1

Comparison of strain energy density values

\begin{tabular}{|c|c|c|}
\hline \multicolumn{2}{|c|}{ Strain energy density, MJ/ $\mathrm{m}^{3}$} & \multirow{2}{*}{ Specific heat of fusion, $\mathrm{MJ} / \mathrm{m}^{3}$} \\
\hline Classic true curve & Complete true curve & 1926.6 \\
\hline 1015 & 1802 & \\
\hline
\end{tabular}

Thus, it can be stated that the complete true curve obtained by the proposed technique gives values of critical stresses and strains closer to the theoretical strength limit of material, which is significantly higher than the engineering ultimate stress [12]. Therefore, the use of a complete true stress-strain curve in the finite element method calculations at large scale yielding conditions will give much more accurate 


\section{Yuriy Molkov, Yaroslav Ivanyts 'kyi, Taras Lenkovs 'kyi, Andriy Trostianchyn, et al.}

results, as well as using critical strain energy density value obtained from the curve for fatigue life-time calculation by energy approach.

\section{Conclusions}

A tensile testing technique for complete true stress-strain curves plotting is developed and the curve for $40 \mathrm{Kh}$ steel is obtained. It is established that strain energy density determined from the complete true stress-strain curve is $80 \%$ higher than determined from the engineering curve and $40 \%$ higher than determined from the classical true curve. The correctness of the energy determination approach is confirmed by closeness of its value to the specific heat of fusion of steel.

\section{Acknowledgements}

This research was supported by the Ministry of Education and Science of Ukraine under the project number 0119U002248 «Improvement of reliability and forecasting of the safe operational life of elements for turbine engines of aviation engineering».

\section{References}

[1] Yu. Du, et al., "Analysis of the stress-strain state of the process zone of a plate with central crack under biaxial loading," Materials Science, vol. 53, no. 1, pp. 86-92, 2017.

[2] Yu. V. Mol'kov, "Experimental determination of the specific strain energy of $65 \mathrm{G}$ steel under cyclic loading," Materials Science, vol. 52, no. 4, pp. 522-529, 2017.

[3] H. J. Shindler, "Strain energy density as the link between global and local ap p roach to fracture", in Proc. of 10th Int. Conf. on Fracture, Honolulu, 2001.

[4] L. F. Gillemot, "Criterion of crack initiation and spreading," Engineering Fracture Mechanics, vol. 8, no. 1, pp. 239-253, 1976.

[5] A. Valiente, "On Bridgman's stress solution for a tensile neck applied to axisymmetrical blunt notched tension bars," J. Appl. Mech., vol. 68, no. 3, pp. 412-419, 2000.

[6] M. A. Sutton, M. Cheng, W. H Peters, et al., "Application of an optimized digital correlation method to planar deformation analysis," Image Vision Comput., vol. 4, no. 3, pp. 143-150, 1986.

[7] B. Pan, K. M. Qian, H. M. Xie, and A. Asundi, "Two-dimensional digital image correlation for in-plane displacement and strain measurement: a review," Meas. Sci. Technol., vol. 20, no. 6, pp. 062001-062007, 2009.

[8] Z. Wang, "On the accuracy and speed enhancement of digital image correlation technique," J. Exper. Mech., vol. 26, no. 5, pp. 632-638, 2011.

[9] Yu. V. Mol'kov, "Otsiniuvannia opirnosti ruinuvanniu yemnostei pid tyskom iz vykorystanniam enerhetychnoho pidkhodu" ["Evaluation of pressure vessels fracture resistance using energy approach"], Ph.D. dissertation, Karpenko physico-mechanical institute of the NAS of Ukraine, Lviv, Ukraine, 2014. [in Ukrainian].

[10] Yu. V. Mol'kov, "Application of the method of digital image correlation to the construction of stressstrain diagrams," Materials Science, vol. 48, no. 6, pp. 832-837, 2013.

[11] A. Kalup, M. Žaludová, S. Zlá, et al., "Latent heats of melting and solidifying of real steel grades", in Proc. 23rd International Conference on Metallurgy and Materials (METAL-2014), Brno, Czech Republic, 2014, pp. 695-700.

[12] Th. H. Courtney, Mechanical behaviour of materials. Long Grove, IL: Waveland Press, 2005. 